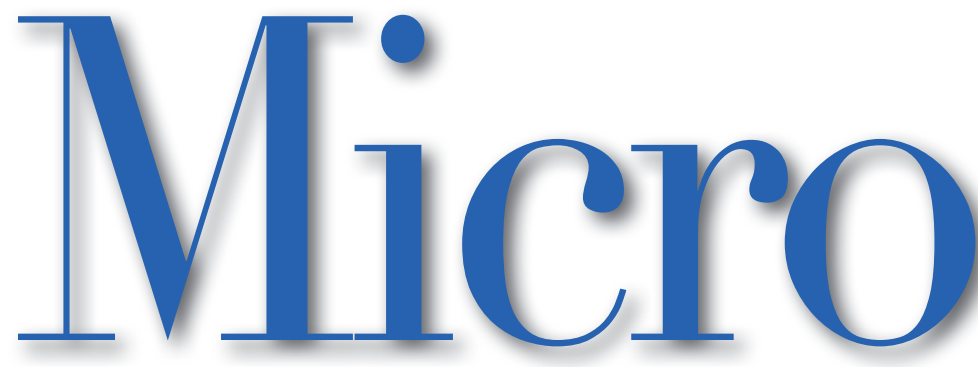

Volume $24 \quad$ Number 52016 September
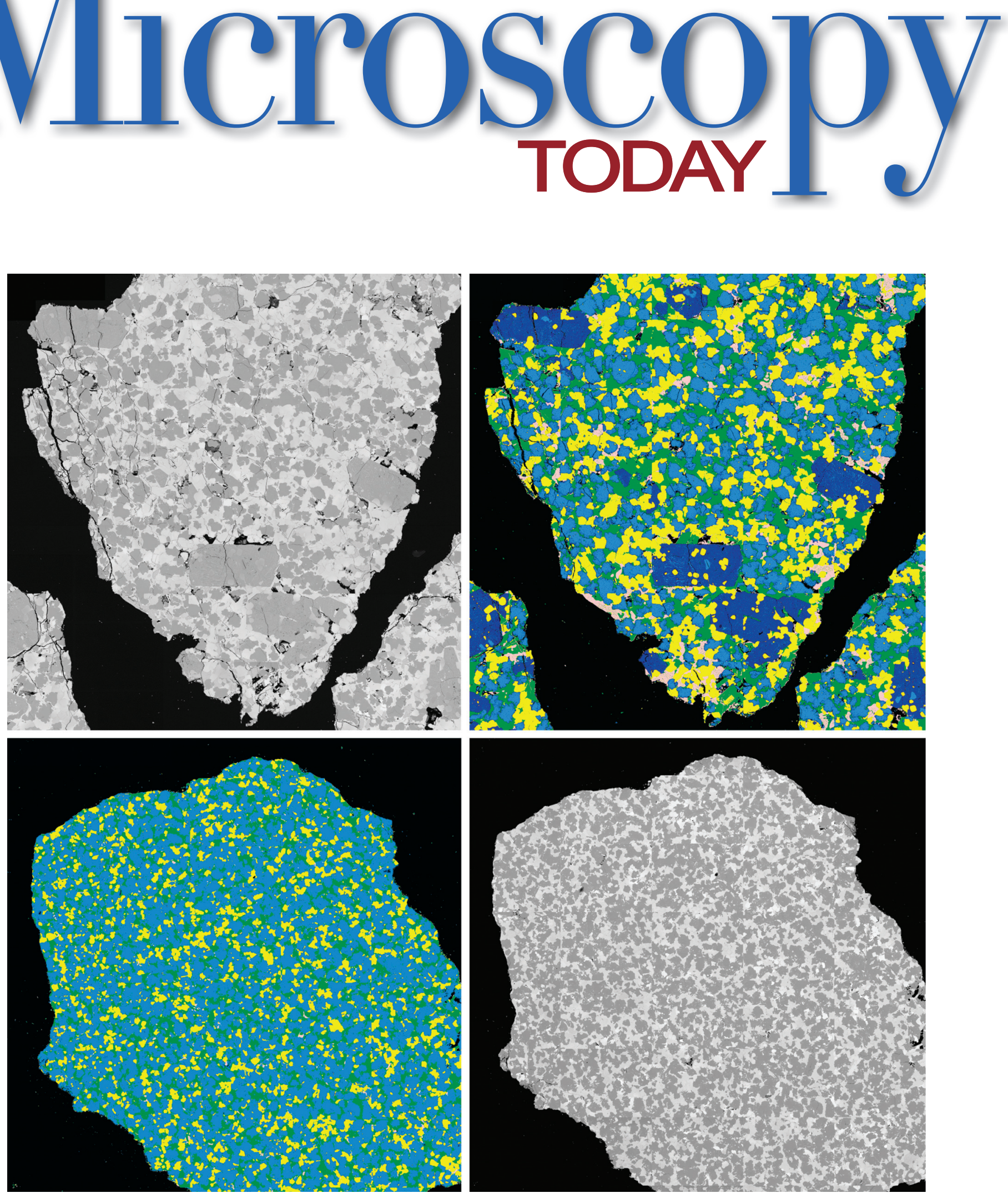
Hitachi strives to provide comprehensive solutions to support your success, not only from inside the lab, but beyond, by providing high-value, innovative, robust, and ergonomic products. Our latest technology demonstrates our commitment to you and the advancement of microscopy.

\section{Think Outside the Lab}

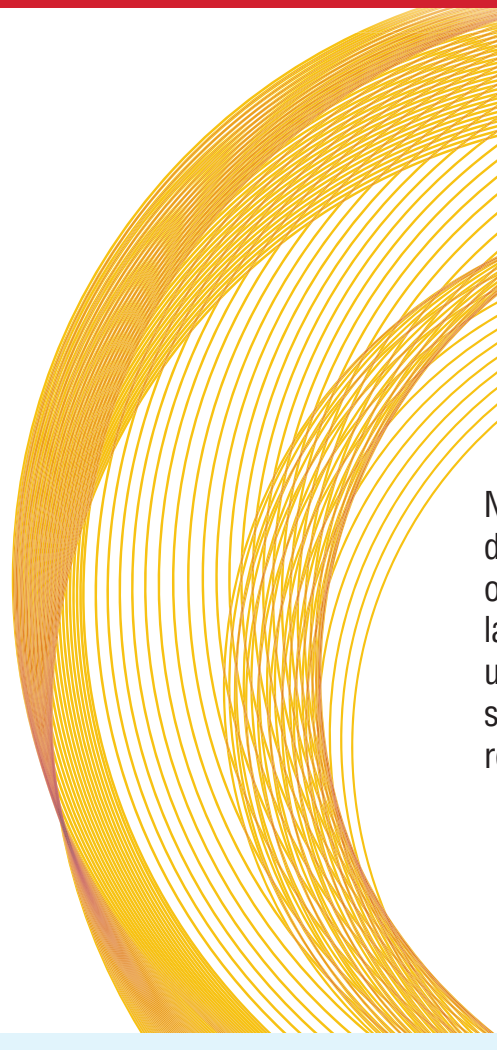

Novel, compact VP-SEM delivering the performance of a conventional SEM in a lab-friendly footprint with a user-friendly GUI, and only standard wall outlet power required.

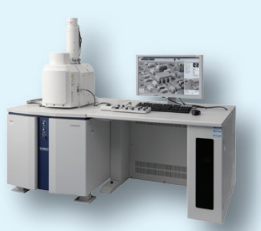

VP-SEM, FE-SEM \& FIB

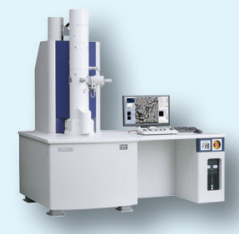

TEM \& STEM

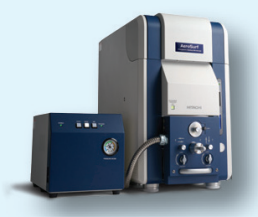

Atmospheric SEM

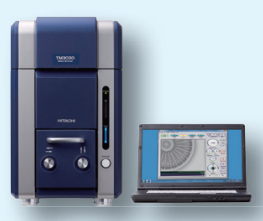

Tabletop SEM

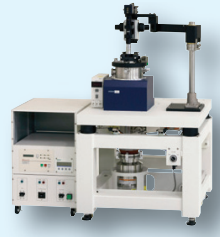

Atomic Force Microscopy

\section{The All New FlexSEM 1000 VP-SEM}

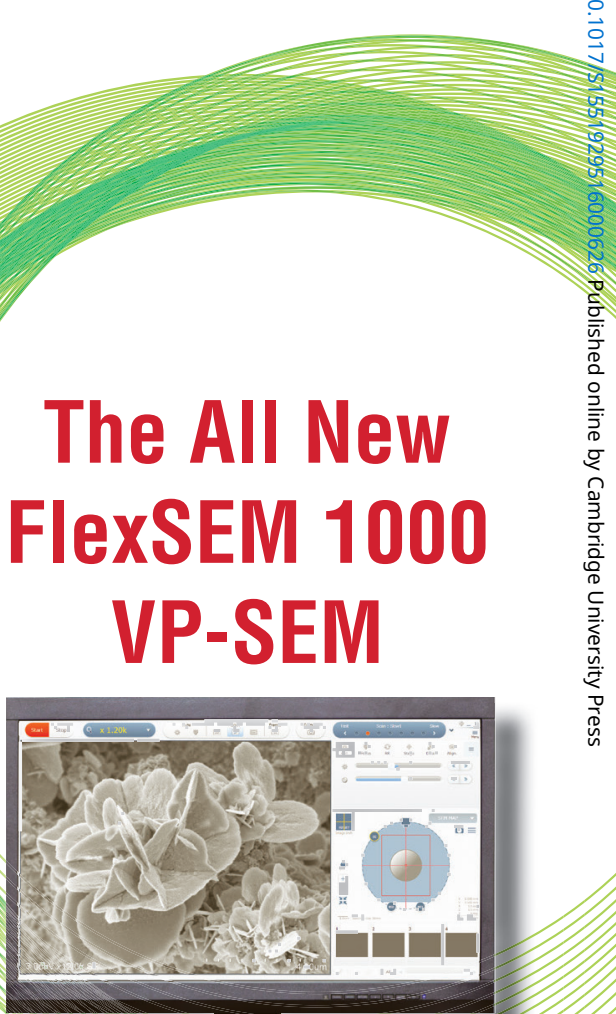

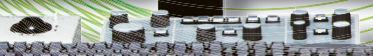

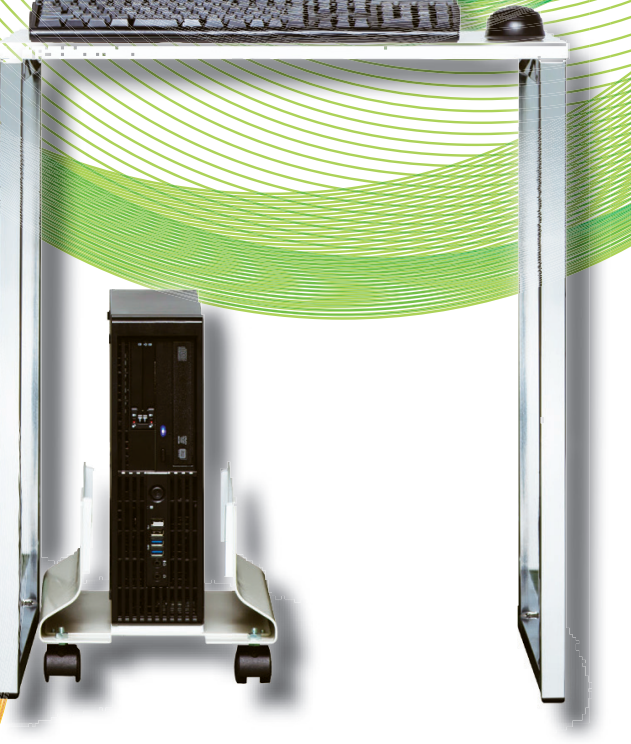




\section{Expand your Knowledge of Microscopy with MSA Membership! Whether your primary focus is in light, electron, or scanning probe microscopy, or the biological or the physical sciences, MSA takes your knowledge to the next level!}

\section{Members Receive:}

- A personal subscription to MSA's official journal, Microscopy and Microanalysis, and MSA's popular bi-monthly magazine, Microscopy Today.

- Peer Networking through the Society's Focused Interest Groups and Local Affiliated Societies.

- Discounts on books, journals and other educational materials.

- MSA Awards Programs, Scholarships, Speaker Opportunities, and more!
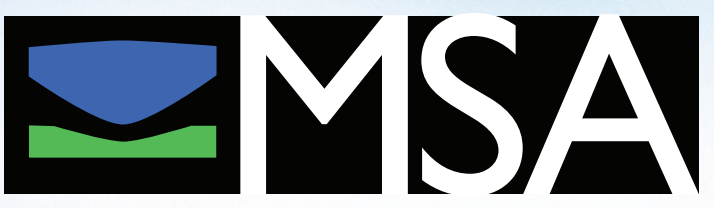

Microscopy Society of America 


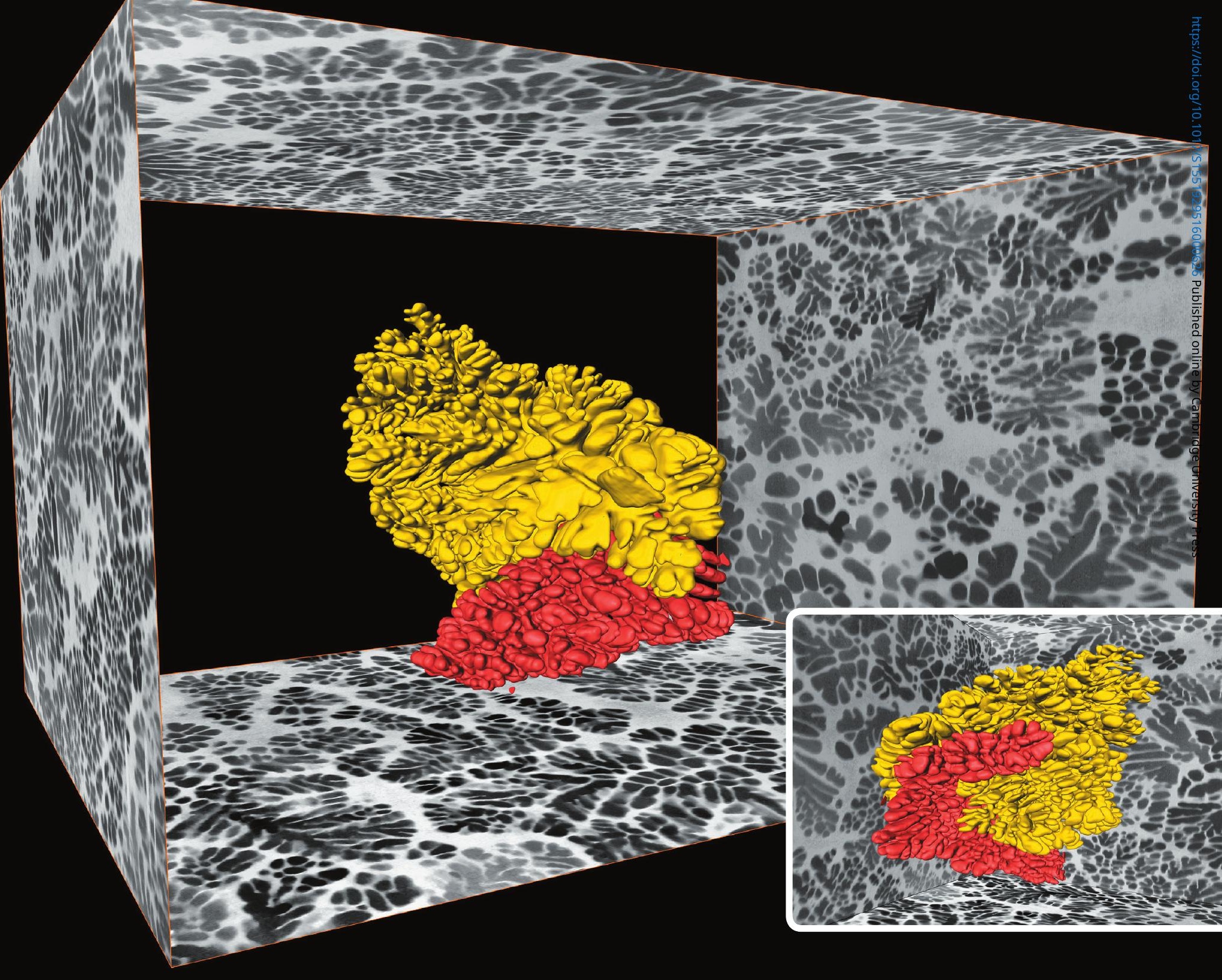

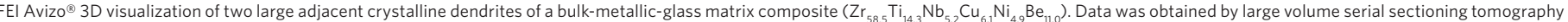
using the Helios PFIB DualBeam. The sectioned block is about $90 \times 80 \times 70 \mu^{3}$ Sample from The University of Tennessee, USA. Images courtesy of The University of Manchester.

\section{Large 3D volumes with \\ unprecedented surface resolution}

Until recently, available technologies have limited the volumes and depths of materials that can be analyzed at high resolution, ultimately restricting the insight into structural, crystallographic, and chemical properties. This is no longer the case. The Helios ${ }^{\mathrm{TM}}$ PFIB DualBeam ${ }^{\mathrm{TM}}$ offers unrivaled access to regions of interest deep below the surface-combining serial section tomography with statistically relevant data analysis. 


\section{Contents}

About the Cover

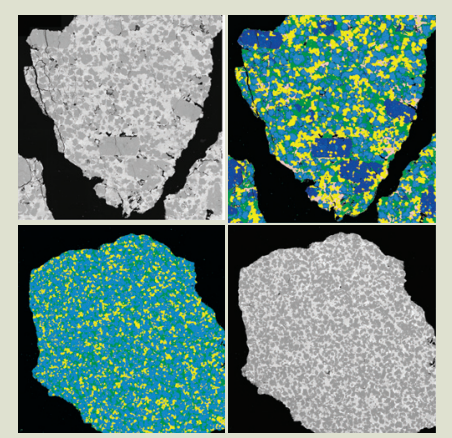

Large-area sections of metallurgical slag grains from steelmaking. Clockwise from upper left: backscattered electron image of lime-bearing grain, phase image of same grain, BSE image of lime-free grain, and phase image of this grain. Image width $=2.56 \mathrm{~mm}$

See article by van Hoek et al.

\section{Microscopy}

\section{Metallographic Phase Analysis}

12 Large-Area Phase Mapping Using $P h A s e$ Recognition and Characterization (PARC) Software

Corrie van Hoek, James Small, and Sieger van der Laan

\section{Secondary Electron Microscopy}

22 Secondary Electron Imaging in an Aberration-Corrected STEM D. R. G. Mitchell and G. Casillas

28 A Reverse Engineering Approach for Imaging Neuronal Architecture Large-Area, High-Resolution SEM Imaging

Christine A. Brantner, Martin Rasche, Kevin E. Burcham, Joseph Klingfus, Joel Fridmann, Jason E. Sanabia, Can E. Korman, and Anastas Popratiloff

\section{Microanalysis}

34 Oxygen X-Ray Maps: Comparing a Vintage WDS System with a Modern SDD System

Aldo Armigliato and Franco Corticelli

\section{Microscopy Innovations}

382016 Microscopy Today Innovation Awards

\section{Opinion}

46 History of the Universe Alwyn Eades

\section{Departments}
7 Editorial
8 Carmichael's Concise Review
44 Pioneers
48 Industry News
50 Product News
52 NetNotes
61 Calendar of Meetings
64 Dear Abbe
66 Index of Advertisers




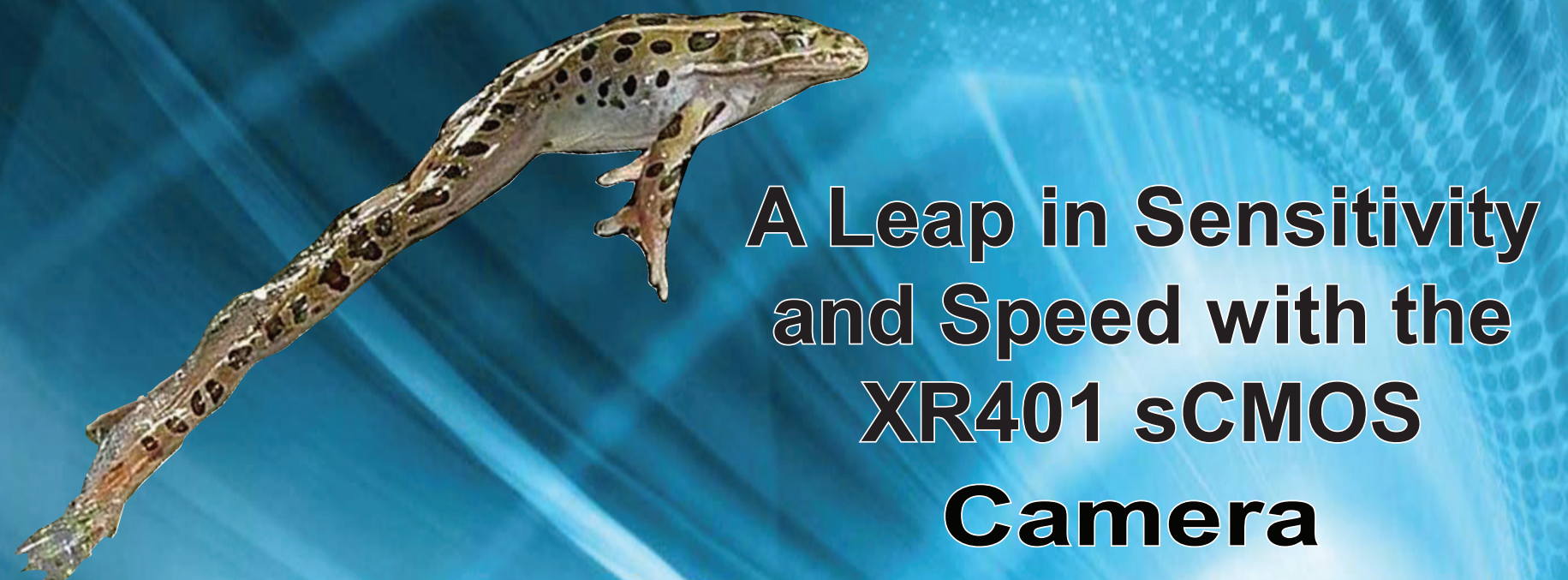

- Cryo TEM

- Low Dose TEM

- Diffraction

- In-Situ TEM

- Extraordinary speed

- Non-Blooming Sensor $0<2$ e/pixel noise

Adenovirus

Dr. Cameron Ackerley

The Hospital for Sick Children

\section{A Leap in Sensitivity and Speed with the XR401 sCMOS Camera}
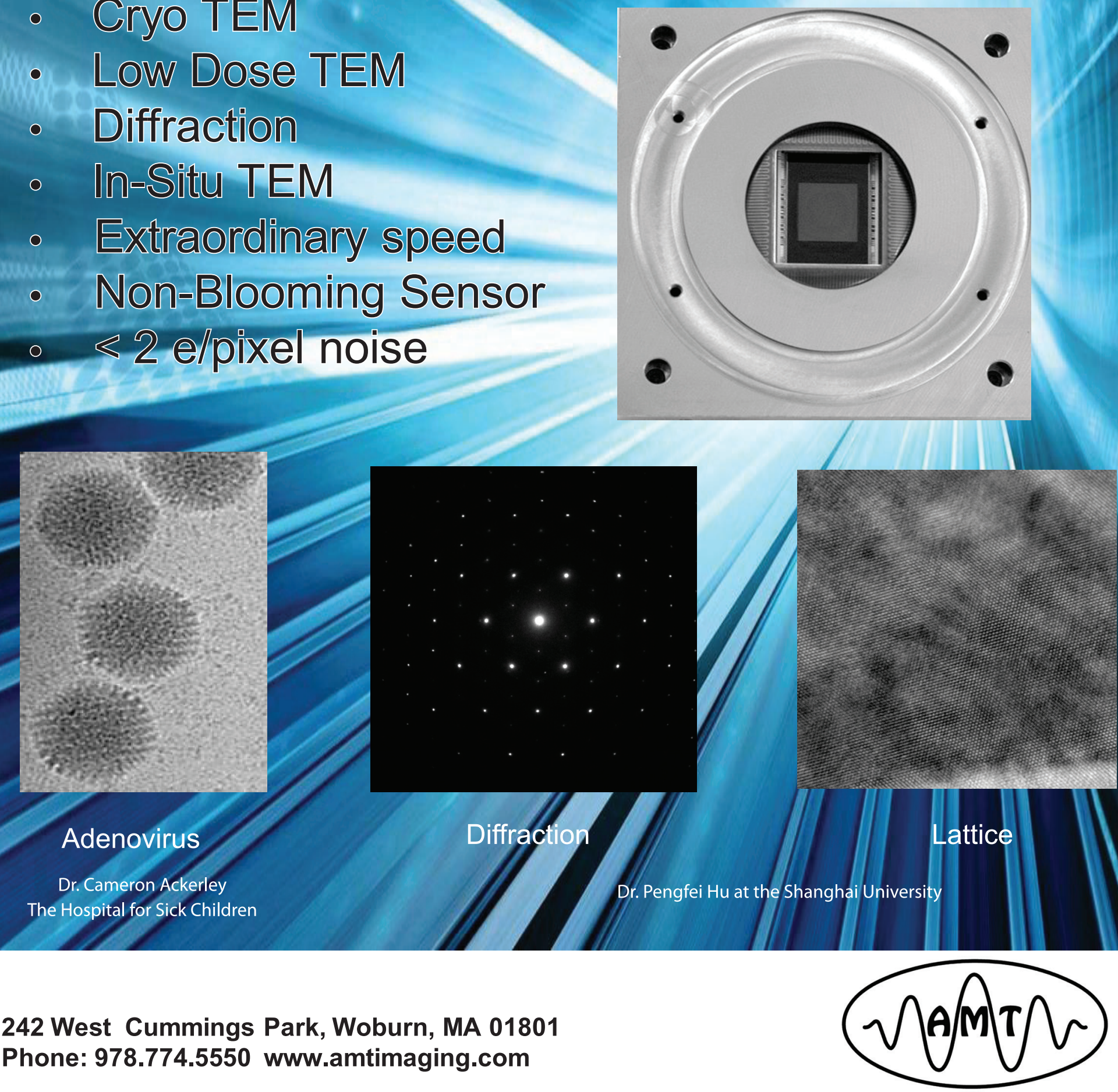